\title{
ASSEMBLEIA LEGISLATIVA DO PARANÁ: a força das linhagens políticas e das relações de parentesco ${ }^{1}$
}

\author{
Mônica Helena Harrich Silva Goulart ${ }^{2}$
}

\begin{abstract}
Resumo: O presente trabalho tem o objetivo de apresentar a Assembleia Legislativa do Paraná a partir das estruturas de parentesco que marcam sua história desde a primeira legislatura republicana, em 1891. Para tanto, se torna relevante a perspectiva teórico-metodológica da conexão família e política para a compreensão das relações de poder e da dinâmica das instituições no estado do Paraná. Tal mapeamento identificou que 12 famílias possuem significativa presença na ALEP, visto que o tempo de linhagem política de certos grupos demarcam mais de um século. A pesquisa valeu-se da análise prosopográfica e genealógica de deputados que tiveram mandatos entre os anos 1935 a 1962 . Dentre esses, muitos sobrenomes estenderam seu poder político pelo fato de familiares continuarem acumulando mandatos parlamentares ao longo do tempo, bem por como estarem presentes desde as atividades iniciais do referido parlamento.
\end{abstract}

Palavras-chave: Famílias, ALEP, Linhagem Política.

\section{PARANÁ LEGISLATIVE ASSEMBLY: the strength of political lineages and kinship relations}

\begin{abstract}
This paper aims to present a Legislative Assembly of Paraná in kinship structures that mark its history since the first republican legislature in 1891. Therefore, a theoretical-methodological perspective of the family and politics for an understanding of the relations of power and of the dynamics of the non state of Paraná becomes relevant. The research identified that 12 families have a significant presence in the ALEP (a Legislative Assembly of Paraná), since the time of political lineage of certain groups demarcate more than a century. The study was based on the prosopographic and genealogical analysis of deputies who had mandates between the years 1935 to 1962. Among these, many surnames extended their political power by the fact that relatives continue to accumulate parliamentary mandates over time, as well as to be present from the initial activities of the mentioned parliament.
\end{abstract}

Key-words: Familys, ALEP, Political Lineage.

Enviado em 15/07/2017

Aprovado em 28/07/2017

\footnotetext{
${ }^{1}$ Uma versão preliminar desse texto foi apresentada no $18^{\circ}$ Congresso Brasileiro de Sociologia. Que Sociologia fazemos? Interfaces com contextos locais, nacionais e globais realizado de 26 a 29 de julho de 2017 no Centro de Convenções Ulysses Guimarães, Brasília/DF.
}

2 Doutora em Sociologia pela Universidade Federal do Paraná- UFPR. Professora Adjunta na Universidade Tecnológica Federal do Paraná - UTFPR. 


\section{Introdução}

O poder legislativo no Brasil tem sido foco de vários estudos, sobretudo após os anos 1990. Análises sobre o parlamento nacional e também sobre as unidades subnacionais se tornaram frequentes a partir de investigações acerca da natureza dos projetos aprovados e da relação entre o executivo e o legislativo. (SANTOS, 2003, 2001; PEREIRA, 2001; ABRUCIO, TEIXEIRA, COSTA, 2001; ANASTACIA, 2001; PEREIRA, 2001; GROHMANN, 2001; ANDRADE, 1998; COUTO, 1998; DOMINGUES, 2001; GOULART, 2014). Conquanto, a aproximação entre política e família, nesse caso entre relações de parentesco engendradas em instituições políticas, não são tão recorrentes como os estudos anteriormente citados.

O presente artigo diz respeito a pesquisa de pós-doutorado desenvolvida no Programa de Pós-graduação em Sociologia, na Universidade Federal do Paraná. Nessa análise foram averiguadas, de forma específica, o conjunto de deputados que fizeram parte das legislaturas de 1935-1937, após a elaboração da Constituição Estadual de 1935, e as legislaturas de 1947-1950, 1951-1954, 1955-1958 e 1959-1962, além do período de elaboração da Constituinte Estadual de 1947. Dessa forma, tal cenário político compreende um conjunto parlamentar formado por 167 deputados, incluindo os suplentes que atuaram momentaneamente nas referidas legislaturas.

Na direção de tal propósito, a Assembleia Legislativa Paranaense é pensada segundo os

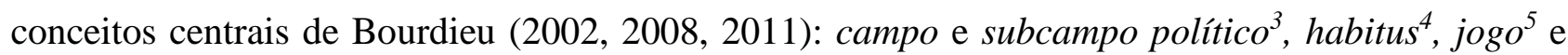
capital ${ }^{6}$ político. Ao se identificar o perfil parlamentar tendo como base os aspectos de formação acadêmica, atuação profissional, filiação político-partidária, ocupação em outros cargos públicos

\footnotetext{
${ }^{3} \mathrm{O}$ campo [e o subcampo - sua parte] político é definido como um espaço relativamente autônomo, dependente de um universo de regras, crenças e papeis próprios. (...) Um microcosmo que comporta fenômenos e objetos que parecem ter existido desde sempre (a democracia, o voto, os partidos políticos, o cidadão eleitor, as sondagens, os deputados), mas que são invenções recentes presas a conjunturas históricas. (CATANI, 2017, p. 91).
}

${ }^{4} \mathrm{O}$ habitus "(...) é uma noção mediadora que ajuda a romper com a dualidade de senso comum entre indivíduo e sociedade ao captar 'a interiorização da exterioridade e a exteriorização da interioridade', ou seja, o modo como a sociedade se torna depositada nas pessoas sob a forma de disposições duráveis, ou capacidades treinadas e propensões estruturadas para pensar, sentir e agir de modos determinados, que então as guiam nas suas respostas criativas aos constrangimentos e solicitações do seu meio social existente." (CATANI, 2017, p. 214).

5 (...) a noção de jogo adquire força sobretudo com referência às lutas específicas travadas em configurações sociais organizadas em diferentes espaços sociais, os campos. Cada campo funcionaria, assim, como um jogo específico, orientado por questões e regras próprias àquele espaço e em torno das quais os agentes lutam para garantir ou incrementar suas posições. (CATANI, 2017, p. 241).

${ }^{6}$ Pode ser pensado como “(...)um 'recurso', segundo o modelo do 'patrimônio', isto é, um estoque de elementos (ou 'componentes') que podem ser possuídos por um indivíduo, um casal, um estabelecimento, uma 'comunidade', um país, etc. Um capital é também uma forma de 'segurança', especialmente do ponto de vista do futuro; tem a característica de poder, em determinados casos, ser investido e acumulado de modo mais ou menos ilimitado.” (CATANI, 2017, p. 101). Podemos pensa-los em várias formas: capital econômico, simbólico, cultural e social, por exemplo. 
e/ou eletivos, o cargo eletivo inicial que promoveu a entrada no espaço político paranaense, percebemos, de forma recorrente, que vários deputados estaduais possuíam relações de parentesco com outros deputados e demais atores políticos importantes do Paraná; questão que será explorada ao longo do texto.

\section{Prosopografia, redes políticas e familiares na ALEP}

$\mathrm{Na}$ tentativa de buscar o perfil parlamentar através da biografia e trajetória política dos deputados que ocuparam a ALEP ao longo de 1935 até 1962, utilizamos como principal recurso a prosopografia. Em linhas gerais e conforme destaca Laurence Stone, a prosopografia “(...) é a investigação das características comuns de um grupo de atores por meio de um estudo coletivo de suas vidas." (STONE, 2011, p. 115). Segundo Stone, ao se levantar informações específicas de um conjunto de atores sociais por meio das biografias coletivas, pode-se identificar a própria realidade social ao mesmo tempo em que também se dá sentido à ação desses indivíduos.

Outro aspecto importante para a presente análise é que as biografias individuais passam por informações de seus familiares e este aspecto indica relações e estratégias de parentesco que interferem na entrada, na permanência e na ascensão ao campo político (CHARLE, 2006). O interessante é que, para alguns casos, o sobrenome familiar permanece no campo, acumulando capitais e incorporando as regras do jogo até a entrada do próximo membro, transferindo uma espécie de legitimidade na ocupação de posições.

Por meio da investigação, mediante as disputas que ocorrem no interior do campo e do subcampo político, percebeu-se o poder de sustentação das famílias, como também a transferência de capital político entre seus membros, como é o caso dos deputados das seguintes parentelas: i) Guimarães; ii) Amaral Ferreira; iii) Ferreira do Amaral; iv) Munhoz da Rocha; v) Ferreira da Cunha Pereira; vi) Camargo; vii) Ribas, viii) Loures Bueno/Rocha Loures, ix) Machado de Oliveira/Martins de Oliveira; x) Macedo, por meio dos ramos Macedo Munhoz, Ribeiro de Macedo Ribas e Borges de Macedo; xi) Anibelli/Lustosa Martins; xii) e Khury. (GOULART, 2016b).

A perspectiva de análise prosopográfica não é recente. Demarcam-se duas escolas iniciais, ambas estabelecidas no período de 1920 a 1930, que contribuíram para o desenvolvimento da prosopografia: i) a escola elitista, direcionada aos estudos de grupos restritos, àqueles que se encontram realmente no poder. Nessa vertente, os aspectos estatísticos não se colocam como 
elementos maiores na análise, embora sejam recursos importantes; ii) e o direcionamento voltado para os estudos das massas, cuja preocupação fundante encontra-se nas correlações estatísticas, além do foco na história social. Aqui os trabalhos também se referem à mobilidade social dos grupos, além do número maior de questões e do número significativo de variáveis (STONE, 2011).

Por meio da análise bourdieusiana, a prosopografia possui papel fundamental na construção de estudos direcionados para agentes sociais que ocupam campos específicos, sendo capaz de perceber as mudanças ocorridas nos respectivos campo e subcampo, assim como inferir quais os capitais envolvidos e de que maneira estes são utilizados quando se está jogando. Na dinâmica que marca os diversos campos da realidade social, a prosopografia e as trajetórias individuais são recursos epistemológicos pertinentes no desvendar das estruturas sociais, indicando suas permanências e alterações. Portanto, ao se estudar as biografias de agentes que fazem parte de um campo, elucida-se a forma pela qual o próprio campo comporta-se ao longo do tempo e ficam evidentes quais regras e posições foram alteradas, bem como os conflitos estabelecidos em seu interior.

No que diz respeito ao contexto histórico, apesar de várias rupturas em relação ao governo varguista, centralizado na força do executivo federal de 1930-45, e do início da democracia competitiva de massas através da incorporação de mais eleitores, Fernando Luiz Abrucio chama a atenção para a retomada (no período pós 1945) da força das oligarquias estaduais, base definidora do então federalismo da República Velha. Pois observa-se que as oligarquias estaduais nesse novo momento passam a compartilhar o poder num cenário em que o federalismo brasileiro também se garante pelo fortalecimento da União e da República, assumindo novos contornos democráticos, mas ao mesmo tempo constrói-se sustentado pelo desenvolvimento social e econômico deixado pelo legado de Vargas. (ABRUCIO, 2002). Nesse caso, a indicação de deputados com cadeiras entre 1935-1962 que tiveram parentes na ALEP da República Velha e posteriormente à 1962, permite apontar a continuidade de grupos familiares (oligarquias) na referida instituição

Por outro lado, a incorporação de novos agentes sociais no processo político entre 19471962 e a construção do pluripartidarismo não foram suficientes para garantir o fim de determinadas famílias no exercício parlamentar, mas o contrário. Conforme o quadro ao final do texto, algumas famílias irão se estabelecer no parlamento estadual justamente a partir do período em questão, tal como as famílias Khury e Anibelli que tiveram seus primeiros mandatos na ALEP, na legislatura de 1955-1958.

Ao se observar as biografias e trajetórias políticas dos deputados e correlacioná-las às suas famílias políticas, constata-se também a continuidade de certos grupos políticos regionais com a 
redemocratização do pós 1985, uma vez que a correlação de forças se estabeleceu justamente pela apropriação de vários cargos públicos pelas mesmas famílias, prioritariamente aliadas aos governadores de estado. Assim, até mesmo parte dos novos atores políticos passam a vincular-se com as famílias tradicionais por meio de casamentos. Segundo aponta Ricardo Costa de Oliveira (2012), no atual estado do Paraná existe cerca de 62 famílias que possuem predomínio nos cargos públicos, tanto eletivos quanto de nomeação, sendo que algumas destas possuem raízes políticas ainda no Império e/ou foram firmadas na República Velha, fato que torna o mecanismo do nepotismo presente nas várias instâncias administrativas.

A presença direta das relações de parentesco torna-se um instrumento eficaz para manutenção do poder político, que é fundamentado, na maioria dos casos, através de redes de poder e de proteção. Segundo Oliveira, as famílias “(...) podem acumular capitais e entrar na classe dominante e também podem paulatinamente ser afastados por um processo de decadência social e econômica. Transformações ocorrem o tempo todo.” (OLIVEIRA, 2001, p. 5).

Em relação à presença da família como forma de capital e consolidação do poder político local e estadual presentes em nossa análise, podemos correlacionar a abordagem de Letícia Bicalho Canêdo (1994), a qual destaca que não se pode desprezar a presença de relações de parentesco como direcionamento e base para o desenvolvimento de redes políticas na forma de ingresso aos cargos eletivos e, principalmente, aos cargos públicos estabelecidos por nomeação. Mesmo numa abordagem que tem como espaço principal a ALEP enquanto subcampo político, não é difícil identificar primeiramente a consolidação dos grupos familiares na esfera do poder local por meio de ocupação de prefeituras e, ao mesmo tempo, a possibilidade de sua ampliação junto ao aparelho regional de Estado, a exemplo da família Macedo que teve expressivo número de membros ocupando a prefeitura da capital, além de atuarem historicamente no judiciário. (GOULART, 2016a, 2016b; OLIVEIRA, 2012).

Investigar a organização política e o perfil dos deputados na ALEP por meio de suas configurações familiares e redes de parentesco nos permite repensar as condições da relação entre as esferas familiares e políticas (e também as condições da República), uma vez que estas não se apresentam separadas em sua práxis, mas, ao contrário, são justamente as formas de ampliação de parentes na política por intermédio de nomeações em cargos públicos administrativos que tais sobrenomes são fortalecidos no estado. Fato esse que também garante sua continuidade nos momentos eleitorais, haja vista a teia de relacionamentos e a ocupação de cargos estratégicos. 
Portanto, essa abordagem sinaliza uma perspectiva de longa duração, pois, segundo Oliveira (2012), os grupos mais importantes que dominam $^{7}$ atualmente a política estadual por meio da presença em cargos políticos e administrativos (comissionados ou não) são vinculados às famílias que consolidaram seu poder político ao longo de três séculos. (OLIVEIRA, 2012).

No que diz respeito a abordagem teórica, Canêdo observa que a partir dos anos 1950 houve um processo de modificação nos estudos sobre política brasileira não tendo mais a família como prioridade da referida relação, pois o foco passou a ser as questões partidárias (e suas siglas) analiticamente apreendidas por meio de abordagens estatísticas; onde o sobrenome e a presença de grupos familiares deixaram de ter relevância enquanto elementos significativos para o embate político institucional no contexto democrático.

Num posicionamento contrário à maioria dos estudos sobre política, no início dos anos 1990 OLIVEIRA $(2001,2004)$ e também CANÊDO $(1994,1995,2005)$ chamam a atenção para a continuidade na esfera política de relações de parentesco. Ambos passaram a considerar em suas investigações a família como variável central para compreensão das relações de poder e da estrutura política e instituicional no Brasil, uma vez que estas são atravessadas por grupos familiares ao longo da histórica e chegam ao contexto contemporâneo com força total.

A dissolução do viés analítico entre família e política nas pesquisas de Sociologia Política, História e Ciência Política ocorreu, segundo Letícia Bicalho Canêdo (2005; 1994; 1997), após grande influência e impacto acadêmico da obra de Maurice Duverger, Os Partidos Políticos ${ }^{8}$ (1967), que direcionou as investigações para os partidos políticos e o sistema partidário. Segundo Canêdo, o aspecto negativo é que a representação política passou a ser vista tão somente por meio do partido e não pela possibilidade de vinculação deste e de seus membros com aspectos ligados à presença da família. Ou seja, ocorreu um processo de dissociação entre as relações sociais que são construídas e também firmadas no campo político de forma a influenciar, em muitos casos, a condução de seu processo.

\footnotetext{
${ }^{7}$ Segundo o autor, e conforme destacado anteriormente, no ano de 2012 foi possível identificar cerca de apenas 62 famílias detentoras dos cargos públicos mais importantes no estado: no Legislativo, no Judiciário, do Executivo, no Ministério Público e no Tribunal de Contas. (OLIVEIRA, 2012).

${ }^{8}$ A contribuição da respectiva obra é fundamental para a consolidação da área e dos estudos de Sociologia Política e de Ciência Política no Brasil, pois permite perceber a estrutura partidária, o processo de aprimoramento do sufrágio universal e mecanismos democráticos de representação social e de grupos de interesse, construídos a partir de um cenário modernizador e um campo político institucionalizado.
} 
Seguindo a influência e perspectiva analítica de OLIVEIRA (2002, 2004, 2012, 2015, 2016) e CANÊDO (1994, 1995, 1997, 2005, 2011), um conjunto de outros autores (GRILL, 2004, 2012; GOULART, 2014, 2015, 2016a, 2016b ; MONTEIRO, 2017; VANALI, CRUZ, 2017; REZENDE，2014; PEREIRA，2016; ALVES，2015; MACHADO，2016; KAMINSK，2013; TABATCHEIK, 2015) vêm produzindo pesquisas mostrando que a racionalização, a burocratização e a modernização do campo político não suprimiu a presença de famílias dominando a política nas mais diferentes esferas de poder, tão menos nos aparelhos da administração Estatal, assim como também direcionando a ação e o rumo de partidos políticos nos estados. Oliveira (2012) chama a atenção para o processo de metamorfose ao qual os grupos dominantes, configurados em famílias e nas relações de parentesco, realizaram ao longo do tempo. Afinal, foram capazes de se manter no poder em meio aos processos de mudança da sociedade brasileira e do aprimoramento de suas inúmeras instituições.

Assim, identificamos que nos anos $1990^{9}$ iniciou-se um processo de retomada do vínculo família e política em estudos que tinham como foco a análise da estrutura e relações de poder, de análise da composição e perfil dos agentes que compõem as instituições públicas e órgãos político administrativos; bem como a reflexão em torno da elevada reprodução política de determinados grupos sociais em cargos eletivos e de nomeação ao longo do tempo, delimitados em famílias (sobrenomes), nas mais variadas esferas do Estado.

Canêdo (1994) aponta a linhagem política como aspecto essencial para compreensão da memória em política e da transmissão do patrimônio político familiar. Para isto, destaca as apropriações dos recursos disponíveis por meio das genealogias, dos estudos dos rituais políticos como fundamentais ao permitirem perceber a longevidade (através de várias gerações, em alguns casos) da autoridade política e a forma pela qual os sobrenomes familiares são inscritos e legitimados na memória coletiva. Na presente análise apreendemos de forma restrita o termo linhagem política, de forma a considerar a temporalidade de poder político da cada família ao mapear a presença na ocupação de cargos políticos desde o primeiro membro familiar. Com essa base, identificamos que algumas famílias no Paraná possuem linhagem política na ALEP de mais de 100 anos pelo fato de sua parentela estar presente na instituição desde as primeiras legislaturas do regime republicano ${ }^{10}$, conforme indica o quadro adensado ao texto.

\footnotetext{
${ }^{9}$ Eni de Mesquita Samara (2004) destaca que na área de História os estudos (gerais) sobre família passaram a ser retomados pelos historiadores a partir de 1994.

${ }^{10}$ Cabe destacar que muitos dos sobrenomes destacados ao longo do texto já estavam presentes na política e instituições do Paraná nos tempos da província. (OLIVEIRA, 2001; ALVES, 2015).
} 
No que tange à esfera da família propriamente dita, o casamento se revela como ponto chave para garantir a força e a longa duração do sobrenome no campo político, pois ordena a regularidade nas escolhas matrimoniais e define a identidade do grupo. Assim, o matrimônio se coloca como trunfo importante no jogo político uma vez que pela conexão de sobrenomes acumula capital simbólico e também pode ser fonte de transferência de poder. (CANÊDO, 2011; OLIVEIRA, 2001).

Também para se pensar a continuidade de certas famílias na ALEP, as contribuições de Alexandre Niess (2012), tendo como parâmetro de observação a sociedade francesa no contexto contemporâneo e de estudos realizados especificamente sobre o período de 1871 a 1940 (Terceira República francesa), tornam-se fundamentais ao indicarem a contradição intrínseca na relação República e hereditariedade política na medida em que tais campos se apresentam inicialmente em espaços distintos e com relações e características particulares. Ou seja, os espaços do mundo público e do mundo privado são díspares. Para o autor, a visualização recorrente entre política e hereditariedade pertence à Monarquia e não à contextos Republicanos. Além do fato de que a questão da "hereditariedade" se coloca como incompatível à perspectiva democrática, fundada em valores como liberdade, direitos, igualdade, propriedade, segurança, representação política, felicidade e, principalmente, pelo sufrágio universal.

Niess entende que a família é um grupo social estabelecido por meio do casamento enquanto átomo inicial. Tal laço, portanto, só pode ser decorrente de outras duas famílias. Mesmo passando pelo reconhecimento de laços que se expandem para além de relações nucleares, o casamento é o vínculo essencial para o entendimento do conceito de família. (NIESS, 20012). Não só para uma família em si, mas para a configuração de novos ramos familiares essa percepção acaba sendo fundamental no esclarecimento das relações entre linhagens familiares e nepotismo, bem como para compreender o percurso que laços de parentesco e certos sobrenomes percorrem ao se ampliar. Como exemplo do caso paranaense tem-se: os ramos Macedo, Ferreira, Munhoz, Oliveira Martins, Loures, Camargo, Guimarães, Anibelli, etc.

Já o conceito de parentesco, para Niess, é entendido pela ampliação de relações humanas e seus vínculos familiares, pressupondo duas conexões básicas: primeiro, estabelecida pelo núcleo familiar básico, a família, e, por outro, pela dilatação desta em outros ramos, definindo relações de parentesco, podendo ser o elemento socialmente fortalecedor do grupo inicial, quanto mais se observado pelo exame da longa duração. Assim, a filiação política pode ser estabelecida, segundo o autor, a partir de duas dimensões: filiações diretas e filiações indiretas (NIESS, 2012). 
Nas filiações diretas, a hereditariedade política se estabelece verticalmente pelas relações entre pais e filhos, ou seja, quando o filho recebe dos pais toda uma herança política exercida anteriormente, fator identificado por pesquisas genealógicas. O peso da tradição familiar é a base para a continuidade e legitimidade do sobrenome nos espaços de poder político, independentemente de suas alterações em esferas diferentes. O que vale, então, é o fato do pai, de certa forma, "preparar" e garantir, de antemão, o terreno político para "receber" seu filho. Podemos apontar os seguintes deputados para a análise da ALEP: a) Alceu Ferreira do Amaral e de Leônidas Ferreira do Amaral que são filhos de João Cândido Ferreira (que foi deputado federal e estadual, governador, prefeito e membro do Conselho Consultivo); b) Caio Gracho Machado Lima, filho de Vicente Machado, um dos políticos mais influentes do Paraná da República Velha (que foi deputado estadual, senador e governador); c) Cândido Machado de Oliveira, filho de João Cândido de Oliveira (negociante, coronel, delegado de polícia, prefeito e deputado estadual); d) José Rodrigues Vieira, filho de Ulysses Falcão Vieira (delegado de polícia, promotor público e deputado estadual); e) Mário Erichsen, filho de Conrado Caetano Erichsen (desembargador e deputado estadual); f) Néo Alves Martins, filho de Romário Martins (historiador, escritor e deputado estadual por vários mandatos); g) Nilson de Jesus Baptista Ribas, filho de Rutílio de Sá Ribas (fazendeiro, deputado estadual e prefeito); h) Ovande Ferreira do Amaral, filho de Joaquim Ferreira do Amaral e Silva (prefeito, vereador e deputado estadual); i) Paulo Afonso Alves de Camargo, filho de Afonso Alves de Camargo (deputado estadual, deputado federal, senador e governador na República Velha); j) Ruy Cunha, filho de Eurides Cunha (pecuarista, deputado estadual, vereador, prefeito e vice-governador, dentre outros exemplos. (GOULART, 2014, 2016b).

Neste ponto, utilizando-se da mesma nomenclatura esboçada pelo referido autor, de filiação direta, consideramos para o presente estudo (ALEP 1935-1962) a ampliação da filiação direta para o caso entre irmãos, haja vista que o primeiro a ingressar na política possui tendência a possuir capital político maior em decorrência do tempo e dos contatos já firmados, além do próprio exercício dos cargos, além do fato de pertencerem ao mesmo átomo inicial. Vale ressaltar que também identificamos a presença de irmãos que ocuparam cargos no referido subcampo, até no mesmo período legislativo. Destacam-se: a) Alceu Ferreira do Amaral, cujo irmão, Leônidas do Amaral Ferreira também fora deputado; b) Alcides Pereira Junior, cujo irmão (padre) Alcidino Gonzaga Pereira obteve quatro mandatos na ALEP entre os anos 1922-1929); c) Caetano Munhoz da Rocha, irmão de Ildefonso Munhoz da Rocha (deputado estadual no período político anterior); d) Elias Nacle, irmão de Fuad Nacle (que teve mandato na ALEP entre os anos 1970-1982); Joaquim Linhares de Lacerda, irmão do deputado estadual Manoel Linhares de Lacerda (ambos 
exerceram mandato em 1951-1954); e) Miguel Buffara, irmão de Nelson Buffara, (que posteriormente exerceu mandatos na ALEP entre 1967-1986); f) Rubem Fleury da Rocha, irmão de João Fleury da Rocha (juiz, prefeito e deputado estadual em três legislaturas), entre outros. (GOULART, 2016b).

Sobre as filiações indiretas, tão significativas quanto a primeira, trata-se da capacidade de hereditariedade política que ocorre entre genros e $\operatorname{sogros}^{11}$. Ou seja, o casamento torna-se um mecanismo fundamental para a escolha e/ou direcionamento do "pertencimento político" a determinado grupo familiar. A entrada que permite o vínculo político é o casamento. Não são raros os exemplos no caso dos deputados paranaenses que receberam capital político por meio do crédito advindo de seus sogros, ou estes reforçaram as credenciais políticas pelo acúmulo de grupos familiares na política, destacando-se: a) Acyr Guimarães, genro de Joaquim Pereira de Macedo (prefeito de Curitiba e membro de família política tradicional); b) Alceu Ferreira do Amaral, genro por duas vezes de Claudino Ferreira dos Santos (deputado estadual, prefeito e secretário de governo); c) Lauro Gentil Portugal Tavares, genro de Zacarias de Paula Xavier (deputado estadual, empresário e um dos fundadores da Associação Comercial do Paraná); Mário Baptista de Barros, genro do empresário Munir Kaluf; d) Ruy Gandara, genro do governador Moysés Lupion. (GOULART, 2016b).

Quanto maior for a carreira política e a rede de parentesco do sogro, maior será o capital agregado pelo genro. Apesar de Niess ter como ponto de observação a política francesa, entendemos que para a realidade brasileira, sobretudo paranaense, a presença de cunhados, tios e primos pode ser considerada como elemento significativo na composição dos vínculos construídos e firmados pelas filiações indiretas. Podemos ilustrar com os referidos deputados: a) Alceu Ferreira do Amaral, tio do deputado Lincoln Ferreira da Cunha Pereira (1955-1962); b) Amaury de Oliveira e Silva, cunhado de Renato Loures Bueno (vereador e também deputado estadual por quatro mandatos); c) Antonio Anibelli, cunhado de Cândido Machado de Oliveira Neto (deputado na ALEP entre 1951-1962) e tio de Luis Alberto Martins de Oliveira (deputado estadual por quatro vezes e senador) ; d) Antonio Augusto de Carvalho Chaves, tio de Eduardo Augusto de Vasconcellos Chaves (comerciante e deputados estadual 1894-1897); e) Eurico Baptista Rosas,

\footnotetext{
11 A ampliação da influência política através do sogro é associada a possibilidade de se creditar no jogo político o sobrenome duplo, ou seja, o sobrenome da esposa pode ser um fator de acréscimo político se o pai tiver um histórico político considerável, resultando na longevidade da linhagem política. Não só o vínculo com outro sobrenome político, mas a sua história também passa a ser apropriada. A incorporação do nome do sogro junto à família do agente político (o genro) é chamada por Niess (2012) de uso do duplo patronímico.
} 
sobrinho de Theodoro Baptista Rosas (prefeito em Ponta Grossa); f) Laertez Macedo Munhoz, primo de segundo grau de Caetano Munhoz da Rocha (deputado estadual, senador, prefeito e governador); g) Lincoln Ferreira da Cunha Pereira, sobrinho neto de Victor Ferreira do Amaral e Silva (médico, deputado estadual e federal, vice-governador e um dos fundadores da Universidade do Paraná); h) Lindolpho Pessoa da Cruz Marques, concunhado de Afonso Alves de Camargo (deputado estadual, senador, deputado federal e governador do Paraná na República Velha); i) Manoel de Alencar Guimarães, sobrinho de Cândido Ferreira de Abreu (prefeito de Curitiba) e de Alberto Ferreira de Abreu (deputado federal); j) Ovande Ferreira do Amaral, sobrinho materno de José Pereira dos Santos Andrade (governador na República Velha); k) Paulo Afonso Alves de Camargo, tio de Afonso Alves de Camargo Neto (senador, deputado federal e ministro nos anos 1980 e 1990), além de cunhado de Bento Munhoz da Rocha Neto (governador do Paraná (19511955); k) Vespasiano Ferreira Pimpão, sobrinho de Domingos Ignácio de Araújo Pimpão (deputado estadual 1912-1913), entre outros. Apesar do sobrenome não ser empregado em alguns casos de parentesco citados anteriormente, a associação dos agentes políticos ao mesmo grupo familiar pode ser pensada como fator de acréscimo, desde que, para isto, ambos atores políticos estejam participando do mesmo lado do jogo político. (GOULART, 2016b).

Ao pensarmos o caso do Paraná, por meio da análise da ALEP, a variável família se impõe como componente significativo. Dos 167 parlamentares mapeados, 81 deputados possuem laços familiares com políticos, o que corresponde a quase metade do conjunto, ou seja, 48, 5\%. (GOULART, 2016b).

Gráfico 1 - Relações de Parentesco Político na ALEP

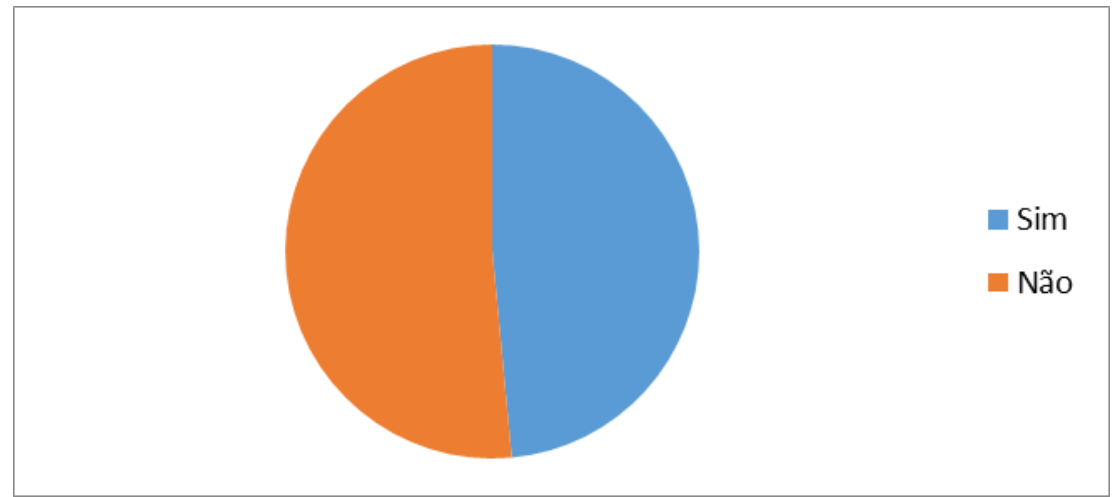

Fonte: GOULART, 2016b. 
Destes 81 deputados, 15 possuem parentes que atuaram ou atuam somente na Assembleia Legislativa do Paraná, e 22 deputados possuem relações de parentesco com políticos que não passaram pela ALEP, mas ocuparam outros cargos eletivos ou de nomeação, como secretários de governo. Dessa forma, destacamos que 44 parlamentares possuem parentes na ALEP e também em outras esferas políticas, aspecto que amplia consideravelmente sua capacidade de articulação política em outros campos de poder. A ilustração abaixo enfatiza a presente questão:

Gráfico 2 - Área de Atuação Política dos Parentes

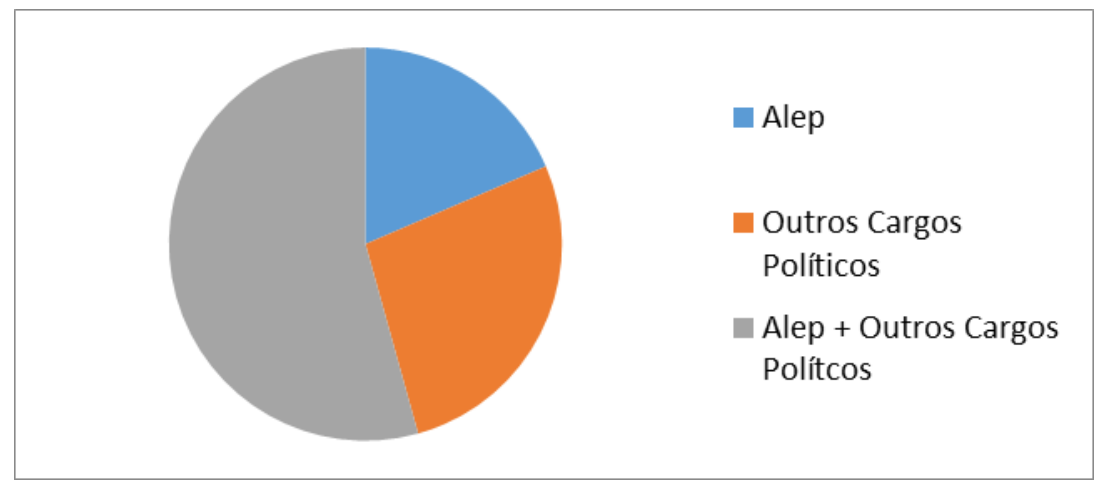

Fonte: GOULART, 2016b.

Isto posto, confirmamos que "família ainda importa" (OLIVEIRA, 2012) para a análise da política e suas mais variadas instituições. A partir do levantamento dos deputados que cumpriram mandatos entre os anos 1935-1962, vale ressaltar que identificamos 12 famílias com expressiva linhagem política e, dentre essas, dois grandes grupos de parentesco que surgem no referido período e que passam a ter papel fundamental na condução da ALEP ao longo do século XX e início do século XXI. Fato empírico que contempla a tese de Ricardo Costa de Oliveira (2012) e de Letícia Bicalho Canêdo de que o estudo das famílias e das relações de parentesco devem ter espaço nas pesquisas de Sociologia Política e de Ciência Política, haja vista que não se pode negar a presença histórica de familiares na ocupação de cargos estratégicos e de que as instituições políticas são atravessadas por poucos sobrenomes.

Enfim, cabe ressaltar que a presente divisão familiar se constitui de um recurso didático para pensarmos famílias em específico. Mas, conforme se pode perceber, alguns nomes compõem mais de uma família tendo em vista a relação entre sogros e cunhados, assim como primos. Em alguns casos consideramos o ramo familiar subdividido porque os vínculos familiares se apresentavam mais claros. Em outros casos, apesar da certeza da conexão familiar, o tipo e grau de parentesco pairava dúvida. Portanto, a relação de parentesco entre os grupos abaixo nos permite 
indicar que a subdivisão realizada poderia ser ainda mais estreita, ou seja, compondo um quadro com menos de 12 troncos familiares. Fato que revela o domínio de poucos grupos ao longo da história da ALEP. Para os demais cargos, foram considerados familiares que exerceram outros tipos de cargos políticos, ainda que não fossem deputados estaduais.

Com intuito de ilustrar a ALEP como instituição permeada ao longo do tempo por certos grupos de parentesco, apontamos por meio do quadro abaixo os principais sobrenomes que acumularam legislaturas durante o contexto republicano perfazendo a linhagem política familiar, bem como a rede parental no campo político paranaense.

Quadro 1 - ALEP e poder político familiar

\begin{tabular}{|c|c|c|c|c|c|c|c|}
\hline Família & $\begin{array}{l}\text { Tempo } \\
\text { de } \\
\text { Linha- } \\
\text { gem } \\
\text { Política }\end{array}$ & $\begin{array}{l}\text { Deputados } \\
\text { na } \\
\text { ALEP } \\
\text { (número de } \\
\text { mandatos) }\end{array}$ & $\begin{array}{l}\text { Membro } \\
\text { no } \\
\text { Governo } \\
\text { do PR * }\end{array}$ & $\begin{array}{l}\text { Membro } \\
\text { no } \\
\text { Senado }\end{array}$ & $\begin{array}{l}\text { Membro } \\
\text { na } \\
\text { Câmara } \\
\text { Federal }\end{array}$ & $\begin{array}{l}\text { Membro em } \\
\text { Secretaria } \\
\text { de } \\
\text { Governo } \\
\text { e/ou } \\
\text { Conselho } \\
\text { Administrat } \\
\text { ivo }\end{array}$ & $\begin{array}{l}\text { Família } \\
\text { Tradicional } \\
\text { Genealogia } \\
\text { Paranaense } \\
\text { ou com } \\
\text { vínculos }\end{array}$ \\
\hline Guimarães & 125 anos & $\begin{array}{l}21 \text { mandatos } \\
\text {-Manoel de Alencar } \\
\text { Guimarães; } \\
\text { - Acyr Guimarães; - } \\
\text { Plauto Miró } \\
\text { Guimarães. }\end{array}$ & Não & $\operatorname{sim}$ & sim & $\operatorname{sim}$ & $\operatorname{sim}$ \\
\hline $\begin{array}{l}\text { Amaral } \\
\text { Ferreira }\end{array}$ & 125 anos & $\begin{array}{l}14 \text { mandatos } \\
\text {-João Cândido } \\
\text { Ferreira; } \\
\text {-Leônidas do Amaral } \\
\text { Ferreira; } \\
\text {-Alceu Amaral } \\
\text { Ferreira; } \\
\text {-Lincoln Ferreira da } \\
\text { Cunha Pereira; } \\
\text {-Caetano Munhoz da } \\
\text { Rocha; } \\
\text {-Claudino Rogoberto } \\
\text { Ferreira dos Santos; }\end{array}$ & sim & - & sim & $\operatorname{sim}$ & $\operatorname{sim}$ \\
\hline
\end{tabular}




\begin{tabular}{|c|c|c|c|c|c|c|c|}
\hline $\begin{array}{l}\text { Ferreira do } \\
\text { Amaral }\end{array}$ & 123 anos & $\begin{array}{l}11 \text { mandatos } \\
\text { - Ovande Amaral; } \\
\text { - Joaquim Ferreira do } \\
\text { Amaral e Silva; } \\
\text {-João Cândido } \\
\text { Ferreira; } \\
\text { - José Ferreira do } \\
\text { Amaral e Silva; } \\
\text {-Victor Ferreira do } \\
\text { Amaral e Silva; } \\
\text {-Octávio Ferreira do } \\
\text { Amaral e Silva; }\end{array}$ & sim & sim & $\operatorname{sim}$ & sim & $\operatorname{sim}$ \\
\hline $\begin{array}{l}\text { Munhoz da } \\
\text { Rocha }\end{array}$ & 113 anos & $\begin{array}{l}16 \text { mandatos } \\
\text {-Caetano Munhoz da } \\
\text { Rocha; } \\
\text {-Ildefonso Munhoz } \\
\text { da Rocha; } \\
\text {-Laertes } \\
\text { MacedoMunhoz; }\end{array}$ & sim & sim & sim & $\overline{s i m}$ & $\operatorname{sim}$ \\
\hline $\begin{array}{l}\text { Ferreira da } \\
\text { Cunha } \\
\text { Pereira }\end{array}$ & 120 anos & $\begin{array}{l}12 \text { mandatos } \\
\text {-Lincln Ferreira da } \\
\text { Cunha Pereira; } \\
\text {-João Cândido } \\
\text { Ferreira; } \\
\text {-Victor Ferreira do } \\
\text { Amaral e Silva; } \\
\text {-Octávio Ferreira do } \\
\text { Amaral e Silva; } \\
\text {-Alceu Amaral } \\
\text { Ferreira; } \\
\text {-José Ferreira do } \\
\text { Amaral; }\end{array}$ & $\operatorname{sim}$ & $\operatorname{sim}$ & $\operatorname{sim}$ & $\operatorname{sim}$ & $\operatorname{sim}$ \\
\hline Camargo & 120 anos & $\begin{array}{l}17 \text { mandatos } \\
\text {-Afonso Alves de } \\
\text { Camargo; } \\
\text {-Lindolpho Pessoa da } \\
\text { Cruz Marques; } \\
\text {-José Pinto Rebello } \\
\text { Jr.; }\end{array}$ & sim & $\operatorname{sim}$ & $\operatorname{sim}$ & $\operatorname{sim}$ & $\operatorname{sim}$ \\
\hline
\end{tabular}




\begin{tabular}{|c|c|c|c|c|c|c|c|}
\hline & & $\begin{array}{l}\text {-Paulo Afonso Alves } \\
\text { de Camrago; } \\
\text {-Marins Alves de } \\
\text { Camargo; } \\
\text {-Fábio de Souza } \\
\text { Camargo; }\end{array}$ & & & & & \\
\hline Ribas & 126 anos & $\begin{array}{l}18 \text { mandatos } \\
\text { - Rutílio de Sá } \\
\text { Baptista Ribas; } \\
\text {-Pretextado Penaforte } \\
\text { Taborda Ribas; } \\
\text {-João Lourenço } \\
\text { Taborda Ribas; } \\
\text {-Augusto Lustosa de } \\
\text { Andrade Ribas; } \\
\text {-Antonio Lustosa } \\
\text { Oliveira; } \\
\text {-Luis Fernando Ribas } \\
\text { Carlindo; } \\
\text { - Bernando Ribas } \\
\text { Carli; } \\
\text { - Fernando Ribas } \\
\text { Carli Filho; }\end{array}$ & $\operatorname{sim}$ & - & sim & sim & sim \\
\hline $\begin{array}{l}\text { Rocha } \\
\text { Loures/ } \\
\text { Loures } \\
\text { Bueno }\end{array}$ & 120 anos & $\begin{array}{l}\text { 11 mandatos } \\
\text { - Renato Loures } \\
\text { Bueno; } \\
\text {-Amaury de Oliveira; } \\
\text { - Sylvano Alves da } \\
\text { Rocha Loures; } \\
\text { - Afonso Alves de } \\
\text { Camargo; }\end{array}$ & sim & sim & $\operatorname{sim}$ & - & sim \\
\hline $\begin{array}{l}\text { Machado de } \\
\text { Oliveira/ } \\
\text { Oliveira } \\
\text { Martins }\end{array}$ & 107 anos & $\begin{array}{l}15 \text { mandatos } \\
\text {-Cândido Machado } \\
\text { de Oliveira Neto; } \\
\text {-Luis Alberto Martins } \\
\text { de Oliveira; } \\
\text {-Cândido Manuel } \\
\text { Martins de Oliveira; } \\
\text {-João Cândido de }\end{array}$ & $\operatorname{sim}$ & $\operatorname{sim}$ & sim & - & $\operatorname{sim}$ \\
\hline
\end{tabular}




\begin{tabular}{|c|c|c|c|c|c|c|c|}
\hline & & $\begin{array}{l}\text { Oliveira; } \\
\text {-Antonio Anibelli*; }\end{array}$ & & & & & \\
\hline $\begin{array}{l}\text { Macedo }- \\
\text { ramos } \\
\text { Macedo } \\
\text { Munhoz, } \\
\text { Ribeiro de } \\
\text { Macedo e } \\
\text { Borges de } \\
\text { Macedo }\end{array}$ & 125 anos & $\begin{array}{l}20 \text { mandatos } \\
\text {-Laertes de Macedo } \\
\text { Munhoz; } \\
\text {-Joaquim Pereira de } \\
\text { Macedo; } \\
\text {-Caetano Munhoz da } \\
\text { Rocha; } \\
\text {-Carlos Ribeiro de } \\
\text { Macedo; } \\
\text {-Oscar Borges de } \\
\text { Macedo Ribas; } \\
\text {-José Borges de } \\
\text { Macedo Ribas; } \\
\text {-Rafael Greca de } \\
\text { Macedo; } \\
\text {-Rosy de Macedo } \\
\text { Pinheiro Lima; }\end{array}$ & $\operatorname{sim}$ & $\operatorname{sim}$ & $\operatorname{sim}$ & $\operatorname{sim}$ & $\operatorname{sim}$ \\
\hline $\begin{array}{l}\text { Anibelli/ } \\
\text { Lustosa } \\
\text { Martins }\end{array}$ & 70 anos & $\begin{array}{l}20 \text { mandatos } \\
\text {-Antonio Anibelli; } \\
\text {-Cândido Machado } \\
\text { de Oliveira Neto; } \\
\text {-Antonio Martins } \\
\text { Anibelli; } \\
\text {-Luis Alberto Martins } \\
\text { de Oliveira; } \\
\text {-Antonio Anibelli } \\
\text { Neto; }\end{array}$ & $\operatorname{sim}$ & $\operatorname{sim}$ & $\operatorname{sim}$ & - & $\operatorname{sim}$ \\
\hline Khury & 70 anos & $\begin{array}{l}13 \text { mandatos } \\
\text {-Anibal Khury*; } \\
\text {-Alexandre Maranhão } \\
\text { Cury; }\end{array}$ & $\operatorname{sim}$ & $\operatorname{sim}$ & $\operatorname{sim}$ & $\operatorname{sim}$ & $\operatorname{sim}$ \\
\hline
\end{tabular}

Fonte: GOULART, 2016b.

* Consideramos os governos interinos (substitutos como vice e como presidentes da ALEP).

\section{Considerações Finas}


É notória a importância de grupos familiares em sociedades simples e tradicionais em relação à estrutura social e organização do poder. Contudo, a presença do fenômeno familiar na política brasileira, sobretudo paranaense, tem se apresentado cada vez mais avolumado, independente de transformações nos contextos políticos, sociais e econômicos.

A análise sobre a constituição do grupo que conduziu a ALEP entre 1935 a 1962 revela que não houve ruptura entre o grupo de parlamentares anteriores (1889-1930), ou melhor, em relação às suas famílias. Nesse sentido pôde-se verificar que 48,5\% dos deputados pesquisados possuem vínculos de parentesco na política estadual (e nacional, em alguns casos).

Assim, do universo de 167 deputados, incluindo os suplentes, somente 12 famílias concentraram mandatos que extrapolaram significativamente o referido contexto. Vale ressaltar que, destas, apenas duas (Khury e Anibelli) construíram seus capitais políticos a partir do período em questão. Todavia seus laços de parentesco indicam que se aproximaram das chamadas famílias tradicionais do Paraná por meio de casamentos, consolidando uma espécie de arranjo político que refletiu em suas posições no campo político e também na ALEP, enquanto subcampo.

\section{Referências}

ABRUCIO, Fernando Luiz. Os Barões da Federação: os governadores e a redemocratização brasileira. 2. ed. São Paulo: Editora HUCITEC, 2002.

ABRUCIO, F. L.; TEIXEIRA, M. A. C.; COSTA, V. M. F. O papel institucional da Assembleia Legislativa Paulista: 1995 a 1998. In: SANTOS, F. (Org.). O poder legislativo nos estados: diversidade e convergência. Rio de Janeiro: Editora FGV, 2001.

ALVES, Alessandro Cavassim. A Província do Paraná e sua Assembleia Legislativa (18531889): a força política das famílias tradicionais. Curitiba: Máquina de Escrever, 2015.

ANASTÁCIA, F. Transformando o legislativo: a experiência da Assembleia Legislativa de Minas Gerais. In: SANTOS, F. (Org.). O Poder Legislativo nos Estados: diversidade e convergência. Rio de Janeiro: FGV, 2001.

ANDRADE, R. de C. (Org.). Processo de governo no município e no estado: uma análise a partir de São Paulo. São Paulo: Editora da Universidade de São Paulo, 1998.

BOURDIEU, Pierre. O campo político. Revista Brasileira de Ciência Política, Brasília, jan./jun., p. 193-216, 2011.

O poder simbólico. 5. ed. Rio de Janeiro: Bertrand Brasil, 2002.

Razões Práticas: sobre a teoria da ação. Campinas: Papirus, 2008. 
CANÊDO, Letícia Bicalho. As metáforas da família na transmissão de poder político: questões de método. Cadernos CEDES, Campinas, v. 18, n. 42, ago. 1997.

Caminhos da Memória: parentesco e poder. Revista Textos de História, Brasília, v. 2, n. 3, p. 85-122, 1994.

Metáforas do Parentesco e a duração em Política. Revista Textos de História, Brasília, v. 3, n.1, p. 82-103, 1995.

Ritos, símbolos e alegorias no exercício profissional da política. In: CANÊDO, Letícia Bicalho. (Org.). O sufrágio universal e a invenção democrática. São Paulo: Estação Liberdade, 2005.

Um capital político multiplicado no trabalho genealógico. Revista Pós Ciências Sociais, Maranhão, v. 8, n. 15, p. 55-75, jan./jun. 2011.

CATANI, Afrânio Mendes [et al.]. (Orgs.). Vocabulário Bourdieu. Belo Horizonte: Editora Autêntica, 2017.

CHARLE, Christophe. Como Anda a História Social das Elites e da Burguesia? Tentativa de Balanço Crítico da Historiografia Contemporânea. In: HEINZ, Flávio Madureira (Org.). Por outra história das elites. Rio de Janeiro: Editora FGV, 2006.

COUTO, C. G. Negociação, decisão e governo: padrões interativos na relação ExecutivoLegislativo e o caso paulistano. In: ANDRADE, R. de C. (Org.). Processo de governo no município e no estado: uma análise a partir de São Paulo. São Paulo: Editora da Universidade de São Paulo, 1998.

DOMINGUES, M. P. Espírito Santo: produção legal e relações entre os poderes Executivo e Legislativo entre 1995 a 1998. In: SANTOS, F. (Org.). O Poder Legislativo nos Estados: diversidade e convergência. Rio de Janeiro: FGV, 2001.

DUVERGER, Maurice. (1967). Os Partidos Políticos. 6. ed. Rio de Janeiro: Zahar Editores.

GOULART, Mônica Helena Harrich Silva. A Dança das Cadeiras: análise do jogo político na Assembleia Legislativa do Paraná (1889-1930). Jundiaí, SP: Paco Editorial, 2014.

As Mulheres na ALEP: uma abordagem prosopográfica. In: OLIVEIRA, Ricardo Costa de. (ORG.). Nepotismo, Parentesco e Mulheres. Curitiba: RM editores, $2016 \mathrm{a}$.

Assembleia Legislativa do Paraná: perfil parlamentar e relações de parentesco (19351962). 213 f. Projeto de Pesquisa relativo ao Estágio Pós-Doutoral em Sociologia, Universidade Federal do Paraná, Curitiba, 2016b.

Entre Famílias e Secretarias: análise do arranjo político administrativo da Paraná (18891930). In: OLIVEIRA, Ricardo Costa de. (Org.). Estado, Classe Dominante e Parentesco no Paraná. Blumenau, SC: Nova Letra, 2015. 
GRILL, Igor Gastal. As Bases das Heranças Políticas no Rio Grande do Sul: parentesco, partidos e redes. Sociedade em Debate, Pelotas, v. 10, n. 2, p. 159-197, ago. 2004.

"Famílias", ascensão social e alinhamentos partidários no Rio Grande do Sul. Revista de Ciências Sociais, Fortaleza, v. 43, n. 2, p. 137-157, jul./dez. 2012.

GROHMANN, L. G. M. O processo legislativo no Rio Grande do Sul: 1995 a 1998. In: SANTOS, F. (Org.). O Poder Legislativo nos Estados: diversidade e convergência. Rio de Janeiro: FGV, 2001.

KAMINSKY, Henry Levi. (2013). Elites e Parentesco no Sistema Judicial Paranaense. 200 f. Dissertação (Mestrado em Sociologia) - Universidade Federal do Paraná, Curitiba.

MACHADO, Vanderlei Hermes. (2016). Do Berço ao Túmulo: família e cartórios no Paraná. 238 f. Tese (Doutorado em Sociologia) - Universidade Federal do Paraná, Curitiba.

MONTEIRO, José Marciano. (2016). A Política como Negócio de Família: para uma sociologia política das elites e do poder político familiar. São Paulo: LiberArs, 2017.

NIESS, Alexandre. Carreiras Políticas e Nepotismo na Terceira República Francesa (1871-1940). Revista Brasileira de Ciência Política, Brasília, n. 8, p.71-100, maio/ago. 2012.

OLIVEIRA, Ricardo Costa de. Estado, Classe dominante e Parentesco no Paraná. Blumenau: Nova Letra, 2015.

. (Org.). Na Teia do Nepotismo: sociologia política das relações de parentesco e poder político no Paraná e no Brasil. Curitiba: Ed. Insight, 2012.

. (Org.). Nepotismo, Parentesco e Mulheres. Curitiba: RM Editores, 2016.

. Notas sobre a política paranaense no período de 1930 a 1945. In: OLIVEIRA, Ricardo Costa de; SALLES, Jefferson de Oliveira; KUNHAVALIK, José Pedro. A Construção do Paraná Moderno: políticos e política no Governo do Paraná de 1930 a 1980. Curitiba: SETI, 2004.

O Silêncio dos Vencedores: genealogia, classe dominante e Estado no Paraná. Curitiba: Moinho do Verbo, 2001.

PEREIRA, André Ricardo. Sob a Ótica da Delegação: governadores e assembleias no Brasil pós1989. In: SANTOS, Fabiano. (Org.). O Poder Legislativo nos Estados: diversidades e convergências. Rio de Janeiro: FGV, 2001.

PEREIRA, Fernando Marcelino. Os Conselheiros do Tribunal de Contas do Estado do Paraná: redes sociais, nepotismo e influência política. Revista NEP, Curitiba, v.2, n.1, p. 1-5, 2016.

SAMARA, Eni de Mesquita. A família brasileira. 2a reimp. 4 ed. São Paulo: Brasileiense, 2004. (Coleção tudo é história, 71).

SANTOS, Fabiano. O poder legislativo no presidencialismo de coalizão. Belo Horizonte: Editora UFMG; Rio de Janeiro: IUPERJ, 2003. (Coleção Origem). 
(Org.). O poder legislativo nos estados: diversidade e convergência. Rio de Janeiro: Editora FGV, 2001.

STONE, Lawrence. Prosopografia. Revista de Sociologia e Política, Curitiba, v.19, n. 39, p. 115137, jun. 2011.

TABATCHEIK, Gabriel. Desvendando os Diários Secretos: uma análise do uso dos cargos em comissão da Assembleia Legislativa do Paraná (2006-2010). 155 f. Dissertação (Mestrado em Sociologia) - Universidade Federal do Paraná, Curitiba, 2015.

VANALI, Ana Christina; CRUZ, Katiano. Um exemplo de "old money” no Paraná: a família Rocha Loures. Revista NEP, Curitiba, v.2, n.2, p. 1-26, 2016. 